\title{
"A STUDY OF CLINICAL PROFILE AND FETOMATERNAL OUTCOME OF OBSTETRIC PATIENTS ADMITTED TO INTENSIVE CARE UNIT": A Prospective hospital-based study
}

\author{
URVASHI MIGLANI ${ }^{1}$, ANJALI PATHAK ${ }^{1}$, POONAM LAUL ${ }^{1}$, SUSHMITA SARANGI ${ }^{1}$, \\ SHALINI GANDHI ${ }^{2}$, SANJEEV MIGLANI ${ }^{3}$, VIJAY KADAM ${ }^{1}$, and ANISH LAUL ${ }^{4}$
}

${ }^{1}$ Deen Dayal Upadhyay Hospital

${ }^{2} \mathrm{KD}$ Medical College Hospital and Research Centre

${ }^{3}$ Sir Ganga Ram Hospital

${ }^{4}$ Maulana Azad Medical College

May 21, 2020

\begin{abstract}
Objectives: To study clinical profile of obstetric patients admitted to intensive care unit and to analyze the relation of demographic factors like age, parity, literacy level, socio economic status, APACHE 2 score and level of delay with fetomaternal outcome. Design: Prospective Cross sectional Observational Setting and Population: Obstetric Admissions to ICU of tertiary hospital in North India Methods: After admission to ICU a detailed history, analysis of basic demographic variables along with level of delay was done. APACHE II score was calculated. These parameters were correlated with fetomaternal outcome. The Chi-square test was used to compare categorical variables. The one-way analysis of variance was used to compare the continuous variables among the strata with Tukey's post hoc test. Outcome: Prolonged ICU stay, maternal mortality, perinatal morbidity, perinatal mortality and long hospital stay. Results: Incidence of obstetric ICU admission was $0.77 \%$. Mean age was $26.03 y e a r s$. Most common indication of ICU admission was obstetrical hemorrhage (37.1\%) followed by hypertensive disorders of pregnancy (25.8\%). Type 1 delay was the most common followed by type 2 delay. Mean APACHE II score was 14.77 \pm 6.85 . Observed mortality rate $(30.6 \%)$ was found to be higher than predicted mortality rate $(25 \%)$. APACHE II score was significantly high in the presence of level $1(\mathrm{p}=0.003)$ and level 2 delay $(\mathrm{p}=0.0001)$. Also, it was significantly increased with the duration of delays. Conclusion: Unbooked and referred cases had high incidence of ICU admission. Presence of delay was associated with poor outcome
\end{abstract}

\section{INTRODUCTION}

Maternal mortality is a grave injury to a family, community and the entire nation. It remains unacceptably high with about 830 women dying from pregnancy or childbirth related complications around the world every day (WHO). Majority (99\%) of all maternal deaths occur in developing countries. Between 1990 and 2015, maternal mortality worldwide dropped by about 44\%from 385 to 216 maternal deaths per 100,000 live births. Despite this progress, the world still fell far short of the Millennium Development Goals target of a $75 \%$ reduction in the global MMR by 2015. Between 2016 and 2030, as part of the sustainable development goals, the target is to reduce the global maternal mortality ratio to less than 70 per 100000 live births. ${ }^{1}$

It is of utmost importance that women at risk must be identified and managed appropriately. "Near miss maternal mortality" or "Severe Acute Maternal Morbidity" (SAMM) is more common than maternal mortality and is defined as "a woman who nearly died but survived a complication that occurred during pregnancy, childbirth or within 42 days after termination of pregnancy".2 As SAMM cases share many characteri- 
stics with cases of maternal mortality ${ }^{3,4}$, therefore understanding and managing SAMM (organ dysfunction/failure) will help to decrease and/or prevent maternal mortality.

To achieve optimal management of women with SAMM, principles of critical care management need to be applied. ${ }^{5}$ Critically ill obstetric patients represent an interesting group with unique characteristics whose management is challenged by the presence of a fetus, an altered maternal physiology and disease specific to pregnancy. ${ }^{5,6}$

The characteristics of these patients admitted to ICU (Intensive care unit) including the sociodemographic factors are a useful tool to guide us in better management of these patients in future. Also, the admission of the obstetric patient to intensive care unit and their outcome is an indirect indicator of health care status of a country. There are three main factors that affect the outcome of emergency presentation during pregnancy. These factors were defined, chronologically, as the lengths of the delays in: (i) the decision to seek care, (ii) reaching an appropriate medical facility, and (iii) the receipt of adequate and appropriate treatment. Socioeconomic and cultural factors, accessibility of facilities and quality of care may independently affect the lengths of these three delays. ${ }^{6}$

Recently the report on "Strategies toward ending preventable maternal mortality (EPMM Strategies), a direction-setting report outlining global targets and strategies for reducing maternal mortality in the Sustainable Development Goal (SDG) period published by WHO in 2015 also reiterates the need to address the social, political, and economic determinants of maternal health and mortality. ${ }^{7}$

In this regard, the present study was designed to evaluate the factors responsible for ICU admission of obstetric patients, to analyze their clinical characteristics, the associated levels of delay \& correlate these with the fetomaternal outcome.

\section{MATERIAL AND METHODS}

This was a prospective observational hospital-based study which was conducted in 10 Bedded Intensive care unit at Deen Dayal Upadhyay Hospital, Hari Nagar, Delhi. 124 obstetric patients admitted to intensive care unit during pregnancy, delivery or within 42 days postpartum, from July 2017 to December 2018 were included in the study.

After admission to ICU, a detailed history was taken from relatives of the patient and also extracted from available medical records.

Basic demographic variables (age, parity, literacy level, socio economic status) of the patient were recorded. Acute Physiology and Chronic Health Evaluation (APACHE II), of each patient was calculated with in 24 hour of intensive care unit admission.

Clinical data regarding diagnosis at the time of hospital admission, indication for intensive care unit admission, mode of delivery, length of ICU stay and hospital stay, interventions if any, treatment administered and maternal and perinatal outcome was collected.

\section{OUTCOME MEASURE:}

1. Maternal survival.

2. Length of intensive care unit stay.

3. Total length of hospital stays.

4. Perinatal morbidity (NICU Admission, Low APGAR Score)

5. Perinatal mortality.

The patients were followed up till discharge or death.

Statistical analysis: The results are presented in frequencies, percentages and mean $\pm \mathrm{SD}$. The Chi-square test was used to compare categorical variables. The one-way analysis of variance was used to compare the continuous variables among the strata with Tukey's post hoc test. The p-value $<0.05$ was considered significant. All the analysis was carried out on SPSS 16.0 version (Chicago, Inc., USA). 


\section{RESULTS}

- The incidence of ICU admission was 0.77\% (124 ICU admission/15982 total obstetric admission).

- Majority of patients were between 20-30 years (80.6\%). Age was not associated with outcome ( $>0.05)$

- $53.2 \%$ cases were unbooked and $55.6 \%$ patients were referred from peripheral hospitals. All the outcomes were significantly worse in referred patients except perinatal morbidity.

- More than one third of the patients were uneducated (39.5\%) followed by below high school (30.6\%), high school-intermediate (21.8\%) and graduate (8.1\%). The maternal mortality ,perinatal mortality and prolonged ICU stay was higher in the uneducated patients. However a significant association could be established only with prolonged ICU stay $(\mathrm{p}=0.001)$.

More than half of the patient belonged to lower class (66.9\%) followed by upper lower (29\%) and lower middle class $(4 \%)$. All the outcomes were worst in patients of lower socioeconomic strata. However, no significant $(\mathrm{p}>0.05)$ association could be established.

- $67.7 \%$ of patients were multiparous. There was no significant association found between parity and the outcomes.

- Admission to ICU was more common in postpartum period (88.7\%) as compared to antenatal period $(11.3 \%)$.

- There was no delay present at any level in $25 \%$ cases. $75 \%$ of patients had delay at single or multiple levels. Presence of delay was significantly associated with prolonged ICU stay $(\mathrm{p}=0.001)$, maternal $\operatorname{mortality}(\mathrm{p}=0.003)$ and perinatal mortality $(\mathrm{p}=0.01)$. The association of outcomes with presence or absence of delay and duration of delays is depicted in Table 1and 2 and Figure 1.

- First level delay was present in $34.7 \%$ cases. Second level delay was present in $50 \%$ cases and it was more than 4 hours in $16.9 \%$ patients. Third level delay was present in $9.7 \%$ patients.

- Presence of $1^{\text {st }}$ and $2^{\text {nd }}$ level delay and their increasing duration was significantly associated with prolonged ICU stay $(\mathrm{p}=0.002)(\mathrm{p}=0.01)$, maternal mortality $(\mathrm{p}=0.001,0.004)$ and perinatal mortality $(\mathrm{p}=0.002 .0 .005)$.

- APACHE II score of 5-9 was most common (28.2\%) and APACHE II score of $<4$ was present only in $0.8 \%$ cases. Mean APACHE II score was $14.77 \pm 6.85$. Table $3-4$ depicts the comparison of APACHE II score with delays and its association with outcomes.

- The post hoc test revealed that APACHE II score was significantly $(\mathrm{p}<0.05)$ high in patients having delay of [?]24 hrs. APACHE II score was significantly higher in the presence of $2^{\text {nd }}$ level delay and it significantly increased as the duration of delay increased $(\mathrm{p}=0.0001)$.

- High APACHE II score was significantly associated with length of ICU stay $(\mathrm{p}=0.001)$, maternal mortality $(\mathrm{p}=0.001)$, perinatal mortality $(\mathrm{p}=0.001)$ and length of hospital stay $(\mathrm{p}=0.008)$.

Most common indication for ICU admission was obstetrical hemorrhage $(37.1 \%)$ followed by hypertensive disorders of pregnancy $(25.8 \%)$.

- Blood and blood product transfusion (83.87\%), mechanical ventilation (66.12\%) and the use of inotropic support (47.58\%) were the major interventions done. Surgical intervention was done in $25 \%$ cases in association with other major interventions. Maternal mortality was decreased in patients who had timely surgical intervention though no significant association was found.

- About half of patients had ICU stay of $>48$ hours (51.6\%). Mean length of ICU stay was 3.18+-2.40.

- Most common mode of delivery was cesarean section (58.1\%).

- $38(30.6 \%)$ patients could not be saved. .

- 30(29.12\%) neonates had low Apgar score and needed NICU admission. 13(12.62\%) patients had intrauterine death of the fetus and another eight $(7.76 \%)$ had early neonatal death in NICU. Five (4.85\%) patients had stillbirth. Perinatal morbidity was seen in $29.12 \%$ subjects and perinatal mortality rate was $31.06 \%$.

- The length of hospital stay was [?]7 days in $58.9 \%$ patients. Mean length was $7.09+-3.49$ days. 


\section{DISCUSSION}

In the present study, which was done over a period of 18 months, incidence of ICU admission was $0.77 \%$ which is comparable to the results of Begum and Padmavat ${ }^{8}$. However, Ozumba et al ${ }^{9}$ in 2018 in their study found a higher incidence of $1.7 \%$ probably due to different admission criteria or due to a large catchment area.

It is obvious that booked status of the patients is associated with better outcome as is also reflected in the present study. In contrast to the present study, Joseph et $\mathrm{al}^{10}$ found increased ICU admission among booked cases. Probably this was due to the referral of these booked cases in complicated stages. ${ }^{10}$

In the present study, referred cases comprised the major part (55.6\%) of the ICU admissions and their outcomes were significantly worse than the direct admissions.

This may be attributed to the fact that the patients who are referred are generally high risk or in critical condition as they could not be managed at the periphery hospital. If this factor is also associated with delay in the transport then the outcome of the referred patients further deteriorates.

Maternal health behavior varies with socioeconomic status and it is also affected by education level. Low socioeconomic status is usually associated with low education status, poor health seeking behavior, unintended and unplanned pregnancy, inadequate antenatal visits, lack of knowledge regarding available health facility benefits and their cultural stigma. These issues are clubbed with logistic problems like inaccessibility to health care and form a vicious circle in this strata. The same is clearly reflected in the present study where patients of lower socioeconomic strata had worse outcomes. Concordant results were found by Panda et al, $64.13 \%$ of the patients admitted to ICU in their study belonged to lower socioeconomic status. ${ }^{11}$

To improve the medical care in obstetric emergency, time is a crucial factor in life threatening conditions. Delay at any level worsens the prognosis of patients because life-threatening conditions may develop without any warning and require prompt treatment.

In the present study, first level delay was present in $65.4 \%$ cases admitted in ICU.

Similar to present study, Ghumare et al found that $27 \%$ delays were at the first level. In $19 \%$ cases mixed delay was present. ${ }^{12}$ Kumari $\mathrm{K}$ et al also observed that first delay was present in $81.8 \%$ of cases and level 1 delay was the most common delay found. ${ }^{13}$

In the present study most, common delay found was the delay at level 1, which is the delay in deciding to seek care. It was mainly due to socioeconomic and cultural characteristics. They were also not educated about the warning sign of any complication by the front-line provider (ASHA) in some cases. An accredited social health activist (ASHA ) is a community health worker instituted by the government of India's Ministry of Health and Family Welfare (MOHFW) as a part of the National Rural Health Mission (NRHM). Their antenatal visits were limited to nutritional supplements and a general check up at the ground level, which might have missed preexisting medical and also obstetrical complications like malpresentation and cephalopelvic disproportion.

The hesitation to seek health care was compounded by cultural taboos and gender bias which further increased the duration of delay. The outcomes worsened significantly with increasing duration of level 1 delay. This again emphasizes the importance of intervention in the first few golden hours.

Second level delay is the delay in reaching the appropriate health care facility and in the present study, it was present in $50 \%$ cases.

Similar to our study Kumari K, et al also found that contribution of second level delay was present in 54.5\% cases. ${ }^{13}$

Second level delay of $<4 \mathrm{hr}$ is present in $33.1 \%$ which was mainly due to geographic distribution of referral center, cost of transportation and unavailability of transport. Second level delay of $>4 \mathrm{hr}$ was found in $16.9 \%$ and was associated with delayed decision of referral by peripheral hospital. Main reasons of referral were non 
availability of NICU, blood bank, ICU facility and facility of cesarean section (lack of functional operation theatre or trained personnel). This results in lack of active intervention in the first few golden hours thus worsening the condition of the patients. Increased duration of level 2 delay was significantly associated with worse outcome.

Third level delay was present in $9.7 \%$ cases in the present study. Presence of third level delay in our tertiary care hospital could probably be explained by disproportionate infrastructural facility in comparison to the patient load. (only single functional emergency operation theatre, no availability of dedicated obstetric ICU facility, a smaller number of beds available in general ICU).

In contrast to present study, Ghumare et al found that third level delay was present in $21 \%$ cases $^{12}$ and Kumari $\mathrm{K}$ et al also found third level delay in $45.5 \%$ cases. ${ }^{13}$ It was higher than the present study which may have been contributed by superadded effect of inadequate specialist services and inadequate blood component transfusion facility. ${ }^{12,13}$

Presence of any delay was significantly associated with worse outcomes. In a multicentric cross sectional study done by Pacagnella et al, any type of delay was observed in $53.8 \%$ of subjects and there was positive association between the presence of any delay and severity of maternal outcome. ${ }^{14}$ Kumari $\mathrm{K}$ et al observed that most of the deaths were associated with multiple levels of delay. ${ }^{13}$

It was observed that the most common indication for ICU admission was obstetrical hemorrhage (37.1\%), followed by hypertensive disorder of pregnancy $(25.8 \%)$. In concordance with the present study, Sodhi et al ${ }^{15}$ and Joseph et al ${ }^{10}$ had similar results but Ozumba et al ${ }^{9}$ found that rupture uterus was the most common indication of ICU admission. Uterine rupture has been remarkably eliminated in most parts of the world but probably low socioeconomic status and poor health-seeking behavior of the subjects in the study (South Ease Nigeria) contributed to this finding. ${ }^{9}$

Mean APACHE II score was $14.77+-6.85$, According to this predicted mortality was $25 \%$ but observed mortality was found to be higher i.e. $30.6 \%$. \% . This was probably due to the infrastructure and logistic constraints of our study area, which is a government organization. There was significant $(\mathrm{p}<0.01)$ difference in APACHE II score in the presence of $1^{\text {st }}$ and $2^{\text {nd }}$ level delay. APACHE II score was significantly $(\mathrm{p}<0.05)$ high in patients having delay of [?]24 hrs. Also, APACHE II score was significantly higher in the presence of $2^{\text {nd }}$ level delay and it was significantly increased as the duration of delay increased $(p=0.0001)$.

In contrast to the present study, Sodhi et al found observed mortality rate (OMR) to be too low as compared to the predicted mortality of $24 \% .{ }^{15}$ This variability can probably be explained as this study was conducted in a private hospital having most of the modern equipment. Our study was conducted in a government setup having limited and conventional resources.

Strengths: It is one of the few studies conducted in a tertiary center of northern India correlating all three levels of delay to fetomaternal outcome thus allowing a genuine root cause analysis at the ground level.

\section{Limitations:}

Level of delay was estimated from the available referral documents or by patients recall method which may have led to inaccurate estimation of level of delay.

\section{Recommendation and Conclusion}

- The results clearly reflect that presence of delay and its increasing duration play a vital role in increasing maternal and perinatal mortality. So concrete steps should be taken to address these issues in a way that they are socially acceptable also. This implies that social and health initiatives taken to decrease duration of level 1 delay will go a long way in decreasing maternal morbidity and mortality.

- It was also evident by results that patients who had timely surgical intervention had less maternal and perinatal mortality. So, at tertiary care level, improvements should be done to bridge the gap between infrastructural facilities and the growing demands by building dedicated obstetric ICU, recruiting 
more trained staff and developing obstetric corridor in every tertiary care hospital to reduce the delay. Facilitating triage and fast tracking of the patients should be done for better outcome.

Acknowledgements: Dr Gargi Chowdhary DNB student Deen Dayal Upadhyay Hospital, Hari Nagar, New Delhi, India

Disclosure of interests : None

\section{Contribution of Authors}

Dr Urvashi Miglani conceptualized the study and planned its execution. Supervised the clinical management and the formation and editing of the manuscript.

Dr Anjali Collected and compiled data of eligible subjects

Dr Poonam Laul Supervised the clinical management and the formation and editing of the manuscript.

Dr Sushmita Sarangi Supervised the clinical management and the formation and editing of the manuscript.

Dr Shalini Gandhi Supervised the clinical management and the formation and editing of the manuscript.

Dr Sanjeev Miglani Supervised the clinical management and the formation and editing of the manuscript.

Dr Vijay Kadam Supervised the clinical management and the formation and editing of the manuscript.

Dr Anish Laul Compiled, edited and formatted the data

Ethics Approval : The procedures of the study received ethics approval from the relevant institutional ethics committee of Deen Dayal Upadhyay Hospital.Date of approval is 14/08/2017. There are no associated reference numbers however for communication we use 14082017.

Funding : None

REFERENCES

1. https://www.mhtf.org/topics/the-sustainable-development-goals-and-maternal-mortality/.

2. World Health Organization Statistics 2014. Part 1: Health related Millennium Development Goals. Cause

3. Cochet L, Pattinson RC, MacDonald AP. Severe acute maternal morbidity and maternal death audit - a rapid diagnostic tool for evaluating maternal care. SAJOG 2003; 93(9): 701-702.

4. Baskett TF. Epidemiology of obstetric critical care. Best Pract Res Clinic Obstet Gynaecol 2008; 22(5):763-774.

5. Soubra SH, Guntupalli KK. Critical illness in pregnancy: An overview. Critical Care Med 2005 Oct;33(10 Suppl):S248-55.

6. Calvello EJ, Skog AP, Tenner AG, Wallis LA. Applying the lessons of maternal mortality reduction to global emergency health. Bulletin of World Health organization 2015; 93: 417-423.

7. Jolivet RR, Moran AC, O'Connor M, Chou D, Bhardwaj N, Newby H, Requejo J, Schaaf M, Say L, Langer A. Ending preventable maternal mortality: phase II of a multi-step process to develop a monitoring framework, 2016-2030. BMC pregnancy and childbirth. 2018 Dec;18(1):258.

8. Begum PR, Padmavati P. Critical Care in Obstetrics: A One Year Prospective Study in A Teritary Care Hospital. IOSR Journal of Dental and Medical Sciences (IOSR-JDMS) 2017; 16 (7): 30-43.

9. Ozumba BC, Ajah LO, Obi VO, Umeh UA, Enebe JT, Obioha KC. Pattern and Outcome of Obstetric Admissions into the Intensive Care Unit of a Southeast Nigerian Hospital. Indian J Crit Care Med. 2018; 22 (1): 16-19.

10. Joseph CM, Bhatia G, Abraham V, Dhar T. Obstetric admissions to tertiary care unit- Prevalence, clinical characterstics and outcomes. Indian J Anaesth 2018; 62: 940-4.

11. Panda SR, Jain M, Jain S. Clinical Profile of Obstetric Patients Getting Admitted to ICU in a Tertiary Care Center Having HDU Facility: A Retrospective Analysis. The Journal of Obstetrics and Gynecology of India 2018; 68(6): 477-481. 
12. Ghumare JP, Padvi NV. Assessment of maternal deaths using three delay model at a tertiary care centre in rural Maharashtra, India: retrospective six-year study. Int J Reprod Contracept Obstet Gynecol 2018; 7: 3043-7.

13. Kumari K, Srivastava RK, Srivastava M, Purwar N. Maternal Mortality in Rural Varanasi: Delays, Causes, and Contributing Factors. Indian J Community Med. 2019; 44(1): 26-30.

14. Pacagnella RC, Cecatti JG, Parpinelli MA, Sousa MH, Haddad SM, Costa ML, et al. Delays in receiving obstetric care and poor maternal outcomes: results from a national multicenter cross-sectional study. BMC pregnancy and childbirth 2014;14: 159.

15. Sodhi K, Bansal V, Shrivastava A, Kumar M, Bansal N. Predictors of mortality in critically ill obstetric patients in a tertiary care intensive care unit: A prospective 18 months study. J Obstet Anaesth Crit Care 2018; 8: 73-8.

Table /Figure Caption List

- Table-1: Association of outcomes with presence or absence of delay and single or multiple delay

- Table-2: Association of outcomes with different level of delay and their duration

- Table-3: Comparison of APACHE II score with delay

- Table-4: Association of outcomes with APACHE II score

- Fig-1: Association of outcomes with presence or absence of delay and single or multiple delay.Table-1: Association of outcomes with presence or absence of delay and single or multiple delay

\begin{tabular}{lllll}
\hline Delay & No. women & Length of ICU stay $>\mathbf{4 8} \mathbf{~ h r s . ~}$ & Length of ICU stay $>\mathbf{4 8}$ hrs. & Maternal morta \\
\hline Any of 3 delay & & No. & $\%$ & No. \\
Yes & 93 & 56 & & 35 \\
No & 31 & 8 & 25.8 & 3 \\
p-value $^{1}$ & & $0.001^{*}$ & $0.001^{*}$ & $0.003^{*}$ \\
Type of delay $_{\text {Single }}$ & 36 & 20 & & \\
Multiple $^{\text {p-value }}{ }^{1}$ & 57 & 36 & 55.6 & 11 \\
\end{tabular}

${ }^{1}$ Chi-square test, ${ }^{*}$ Significant

Table-2: Association of outcomes with different level of delay and their duration

\begin{tabular}{|c|c|c|c|c|}
\hline Delay & No. women & Length of ICU stay $>48 \mathrm{hrs}$. & Length of ICU stay $>48 \mathrm{hrs}$. & Maternal morta \\
\hline $1^{\text {st }}$ level & & No. & $\%$ & No. \\
\hline No delay & 43 & 14 & 32.6 & 6 \\
\hline$<24$ hrs. delay & 39 & 20 & 51.3 & 10 \\
\hline $\begin{array}{l}24 \text { hrs. delay } \\
\text { p-value } \\
2^{\text {nd }} \text { level }\end{array}$ & 42 & $\begin{array}{l}30 \\
0.002^{*}\end{array}$ & $\begin{array}{l}71.4 \\
0.002^{*}\end{array}$ & $\begin{array}{l}22 \\
0.001^{*}\end{array}$ \\
\hline No delay & 62 & 24 & 38.7 & 11 \\
\hline 4 hrs. delay & 41 & 25 & 61.0 & 16 \\
\hline$>4$ hrs. delay & 21 & 15 & 71.4 & 11 \\
\hline $\begin{array}{l}\text { p-value } \\
3^{\text {rd }} \text { level delay }\end{array}$ & & $0.01^{*}$ & $0.01^{*}$ & $0.004^{*}$ \\
\hline
\end{tabular}




\begin{tabular}{|c|c|c|c|c|}
\hline Delay & No. women & Length of ICU stay $>48 \mathrm{hrs}$. & Length of ICU stay $>48 \mathrm{hrs}$. & Maternal morta \\
\hline No delay & 112 & 59 & 52.7 & 36 \\
\hline$<6$ hrs delay & 12 & 5 & 41.7 & 2 \\
\hline$>6$ hrs delay & 0 & 0 & 0 & 0 \\
\hline p-value ${ }^{1}$ & & 0.46 & 0.46 & 0.26 \\
\hline
\end{tabular}

${ }^{1}$ Chi-square test, ${ }^{*}$ Significant

Table-3: Comparison of APACHE II score with delay

\begin{tabular}{|c|c|c|}
\hline Delay & APACHE II score & p-value ${ }^{1}$ \\
\hline \multicolumn{3}{|l|}{$1^{\text {st }}$ level } \\
\hline No delay & $11.95 \pm 5.66^{\mathrm{a}, \mathrm{b}}$ & $0.003^{*}$ \\
\hline$<24$ hrs. delay & $15.77 \pm 7.36^{\mathrm{a}}$ & $? i ?$ \\
\hline $\begin{array}{l}24 \text { hrs. delay } \\
\mathbf{2}^{\text {nd }} \text { level }\end{array}$ & $16.74 \pm 6.67^{\mathrm{b}}$ & \\
\hline No delay & $12.60 \pm 6.33^{\mathrm{a}, \mathrm{b}}$ & $0.0001 * ? \gtreqless ?$ \\
\hline 4 hrs. delay & $15.85 \pm 6.21^{\mathrm{a}}$ & \\
\hline $\begin{array}{l}>4 \text { hrs. delay } \\
3^{\text {rd }} \text { level delay }\end{array}$ & $19.10 \pm 7.25^{\mathrm{b}}$ & \\
\hline No delay & $14.86 \pm 7.00$ & 0.68 \\
\hline$<6$ hrs delay & $14.00 \pm 5.47$ & \\
\hline
\end{tabular}

${ }^{1}$ ANOVA test, ${ }^{*}$ Significant,,${ }^{\mathrm{a}, \mathrm{b}} \mathrm{p}<0.05$ (Post hoc tests)

Table-4: Association of outcomes with APACHE II score

\begin{tabular}{lllll}
\hline Interventions & No. women & Length of ICU stay $>\mathbf{4 8}$ hrs. & Length of ICU stay $>\mathbf{4 8}$ hrs. & Maternal mortali \\
\hline & & No. & $\%$ & No. \\
54 & 1 & 0 & 0.0 & 0 \\
$5-9$ & 35 & 5 & 14.3 & 3 \\
$10-14$ & 34 & 22 & 64.7 & 2 \\
$15-19$ & 25 & 19 & 76.0 & 7 \\
$20-24$ & 18 & 11 & 61.1 & 16 \\
$25-29$ & 5 & 4 & 80.0 & 4 \\
$30-34$ & 6 & 3 & 50.0 & 6 \\
p-value $^{1}$ & & $0.001^{*}$ & $0.001^{*}$ & $0.001^{*}$ \\
\hline
\end{tabular}

${ }^{1}$ Chi-square test, ${ }^{*}$ Significant

\section{Hosted file}

Figures.doc available at https://authorea.com/users/324795/articles/452899--a-study-ofclinical-profile-and-fetomaternal-outcome-of-obstetric-patients-admitted-to-intensivecare-unit-a-prospective-hospital-based-study 